\title{
El SAlVAdor: EleCCIONES Y MOVIMIENTOS SOCIALES
}

El Salvador: Elections and Popular Movements

\section{PAUL ALMEIDA}

Universidad de California, Merced

\section{RESUMEN}

Esta investigación se enfoca en las elecciones presidenciales e históricas en El Salvador en 2009. Hay un énfasis dado a la transformación del partido político FMLN en la era después de la guerra civil y la alianza entre el partido y los movimientos sociales en la sociedad civil. La combinación de los procesos de la democratización y las políticas de liberalización económica en los 1990 y 2000 aportó al reforzamiento de la coalición entre el partido de la izquierda y los movimientos populares. Gradualmente el FMLN se podía canalizar la energía de las campañas de los movimientos sociales contra las políticas neoliberales y opinión pública en triunfos electorales al nivel local, parlamentario y Ejecutivo.

Palabras clave: Movimientos sociales, partidos políticos, elecciones, El Salvador.

\begin{abstract}
This article examines the historic presidential elections in El Salvador in 2009. Special attention is given to the evolution of the FMLN political party in the post-civil war era and its relationship with social movements in civil society. The combined forces of democratization and neoliberal policy implementation in the 1990s and early 2000s assisted in strengthening the alliance between the leftwing political party and popular movements. The FMLN was able to gradually channel the momentum of social movement campaigns against economic liberalization policies and public opinion into electoral gains at the local, parliamentary and executive levels of government.
\end{abstract}

Key words: Social movements, political parties, elections, El Salvador. 
El triunfo del candidato del Frente Farabundo Martí para la Liberación Nacional (FMLN), en las elecciones de marzo de 2009 significó un cambio importante a la vez en la historia y en la política reciente de El Salvador. Sin embargo, pocos meses después de haber tomado posesión el nuevo presidente, nuevas divisiones emergieron entre Mauricio Funes y el FMLN. De igual modo, también el otrora partido hegemónico ARENA está experimentando divisiones más graves en su seno. Este artículo examina las condiciones económicas y políticas de la postguerra que llevaron a la victoria del FMLN en el 2009. Igualmente analiza los conflictos entre las elites que han irrumpido desde la asunción del FMLN del poder. Finalmente, analiza la relación entre el partido político FMLN y los movimientos sociales, como antesala de esta victoria.

Las elecciones presidenciales de 2009 fueron un momento crucial en la historia política de El Salvador ya que el derechista Alianza Republicana Nacionalista (ARENA) había mantenido el Poder Ejecutivo desde 1989. La falta de alternancia en el poder presidencial había puesto en tela de juicio las credenciales de la democracia salvadoreña en la era posterior a la guerra civil (Wolf, 2009). El partido ARENA, pro-neoliberal, había ganado cuatro elecciones presidenciales consecutivas durante un período de 15 años (1989-2004). Estas victorias por amplios márgenes le habían dado carta blanca al partido gobernante en aplicar políticas regresivas de liberalización económica, eso sí, con el apoyo legislativo de pequeños partidos conservadores como el Partido de Conciliación Nacional (PCN) y el Partido Demócrata Cristiano (PDC). El triunfo de Mauricio Funes en alianza con el FMLN en la carrera presidencial de 2009 apareció para empujar más a El Salvador en el camino hacia un sistema competitivo electoral multipartidista con el potencial de reformar muchas de las políticas económicas excluyentes imperantes.

En la madrugada del 15 de marzo, voluntarios del Frente Farabundo Martí para la Liberación Nacional se reunieron en el parqueo de la estación de gasolina ESSO en el centro de San Salvador, allí recibieron sus uniformes y equipamientos de parte de los responsables del FMLN para efectuar su labor de supervisores de lo que iba a convertirse en las históricas elecciones presidenciales de 2009. Cerca de las 4:30 am unos 500 voluntarios y vigilantes electorales del FMLN, la gran mayoría aparentemente menores de 35 años, se pusieron en filas e iniciaron su caminata hacia el segundo centro de votación más importante de San Salvador, el Instituto Nacional General Francisco Menéndez (INFRAMEN), uno de los más antiguos centros de enseñanza secundaria de El Salvador, situado a algunas cuadras del lugar de la reunión. Mientras los jóvenes voluntarios se dirigían al INFRAMEN, iban cantando canciones de protestas, rememorando los momentos más álgidos de las protestas populares de la década de 1970. El repertorio incluía "la marcha de la unidad" y canciones del grupo popular Yolocamba Ita. Los vigilantes en marcha parecían más un movimiento social que miembros de un partido institucionalizado (dicho sea de paso una escena similar se observó en el centro de votación Francisco Morazán, situado en el norte de San Salvador).

Antes de las $5 \mathrm{pm}$, horas de cierre de las urnas, se rumoraba la victoria que había triunfado el candidato del FMLN, Mauricio Funes, sobre el candidato del Partido 
Alianza Republicana Nacionalista (ARENA), Rodrigo Ávila (antiguo director de la Policía Nacional Civil). Mientras los vigilantes electorales de los partidos ARENA y FMLN contaban los votos en el centro de votación del Instituto Francisco Menéndez, se podían escuchar las voces de victoria al final del conteo de cada mesa. Si era ARENA que ganaba la mayoría de votos de la mesa, los vigilantes del partido gritaban “¡Patria Sí, Comunismo No!,", si era el FMLN el que ganaba la mayoría de votos de la mesa sus simpatizantes gritaban “¡Un paso al frente, con el Frente!”.

Al final, el FMLN ganó muchas más mesas que ARENA en ese gran centro urbano de votación. Ya a las seis de la tarde, manifestaciones espontáneas de celebración se organizaron en las calles de San Salvador y en otras ciudades del país. Por ejemplo, en la calle San Antonio Abad, cerca de la esquina suroeste de la Universidad de El Salvador, centenares de jóvenes se lanzaron a las calles, con la bandera roja del FMLN, gritando su alegría. Ya a las siete de la noche los reportes televisivos anunciaron la victoria del partido de izquierda. Una multitud empezó a reunirse en el redondel Masferrer cerca del distrito de residencia de las elites salvadoreñas, la Escalón, desde donde el presidente electo, Mauricio Funes, y el vicepresidente electo, Salvador Sánchez Cerén, se dirigirían cerca de la medianoche a más de 50.000 personas congregadas para la ocasión.

Funes asumió la presidencia el primero de junio de 2009, marcando la primera transferencia de poder pacífica a un partido de izquierda en los 188 años de vida republicana salvadoreña (tal vez exceptuando el caso del breve episodio del Partido Laborista de 1931 del presidente Arturo Araujo). ¿Cómo explicar lo sucedido? La victoria sin precedentes de Funes y la participación histórica que significó se entiende mejor como el resultado de una alianza del FMLN con los movimientos sociales. Esta alianza partido-movimiento, realizada al final de la década de los 90 y la primera década del siglo XXI, fue forjada en el contexto de dos fuerzas desatadas en la era posterior a la guerra fría: democratización y neoliberalismo.

El proceso de democratización salvadoreña empezó con la firma de los Acuerdos de Paz, en enero de 1992, la cual puso fin a 12 años de guerra civil y abrió el espacio político para los movimientos sociales y los partidos políticos de oposición. El Salvador es uno de los países en donde los militares han pasado más tiempo en el poder durante el siglo XX. Mientras el país experimentó algunos momentos de liberalización al final de las décadas de 1920, 1960 y 1980, fue hasta la década de 1990 que ocurrió una transición realmente democrática (Almeida, 2008a; Gould and Lauria-Santiago, 2008; Lindo-Fuentes, Ching y Lara-Martínez, 2007). Alguna forma de gobierno militar estaba en vigor desde finales de 1931 hasta 1982, y las fuerzas armadas salvadoreñas siguieron teniendo una influencia enorme dentro del Estado hasta el 1992, fecha en que se negociaron los acuerdos de paz bajo los auspicios de las Naciones Unidas (Stanley, 1996; Williams and Walter, 1997). Solamente los partidos de centro y extrema derecha participaron en las elecciones que se celebraban en la década de 1980 (Artiga-González, 2004), mientras que entre 1980-1987 estaba en vigor un estado de emergencia. Estas condiciones obstaculizaron la capacidad de los movimientos sociales para organizar protestas no violentas por más de unas pocas semanas a 
la vez. Mientras tanto, el gobierno salvadoreño en muchas ocasiones durante los años ochenta alegó que los sindicatos y las organizaciones civiles más importantes mantenían vínculos clandestinos con el FMLN, que entonces era una insurgencia armada. Por ello, los líderes de estas organizaciones civiles eran víctimas de distintas formas de represión, situación que duró hasta principios de los años 1990 (Brockett, 2005).

Poco después de los Acuerdos de Paz, el FMLN recibió el reconocimiento legal como partido político. Este hecho es importante para la paz social, por el simbolismo que representa el hecho de que un antiguo ejército insurgente entregaba sus armas para, en adelante, empezar a participar en las elecciones. Esta nueva realidad repercutió en el comportamiento de los movimientos sociales, que aprovecharon la presencia de un aliado dentro del sistema político (el FMLN), una disminución relativa en la represión por parte de la recién creada Policía Nacional Civil, el desmantelamiento de las antiguas fuerzas de seguridad como la Guardia de Hacienda, Policía Nacional y la Guardia Nacional, tristemente notorias por la represión que ejercieron en el pasado, para movilizarse en las calles.

Mientras tanto, un nuevo modelo económico estaba siendo impuesto en la región: la liberalización económica (Robinson, 2008). Inclusive antes que la guerra civil acabase los gobiernos salvadoreños promulgaron distintos programas de estabilización económica siguiendo los lineamientos del Fondo Monetario Internacional (FMI), como el llevado a cabo por el presidente democratacristiano José Napoleón Duarte en enero de 1986, que incluyó la devaluación de la moneda nacional. Sin embargo, el triunfo del candidato del partido ARENA, Alfredo Cristiani en 1989, significó una profundización en las políticas neoliberales (Robinson, 2003). Durante la presidencia de este último (1989-1994) se llevaron a cabo varias reformas neoliberales, incluida la reprivatización del sistema bancario, el cierre del Instituto Regulador de Abastecimiento (IRA), despidos masivos en el sector público y la privatización de los institutos de exportación de café y refinerías de azúcar.

La democratización y la embestida de la reestructuración neoliberal marcaron el contexto del FMLN como partido político y mantuvieron unidos a sus miembros mientras se convertía en el partido de oposición más importante del fin de la guerra civil. Aunque estas fuerzas se demoraron en converger y producir la alianza estratégica entre los movimientos sociales y el FMLN de finales de 1990 y principios de 2000, finalmente ello llevó al triunfo del partido de izquierda en las elecciones presidenciales de marzo de 2009.

El FMLN se encontraba en transición en la década de 1990 en sus esfuerzos por constituirse como una importante fuerza electoral. Muchos de sus principales dirigentes, con conexiones a los movimientos populares, como Humberto Centeno de la asociación de trabajadores de las telecomunicaciones (ASTTEL), deenfatizaron su militancia social para enrolarse en la movilización electoral del FMLN. Centeno, por ejemplo, pasó a ser diputado y coordinador de las elecciones para el FMLN en 
el departamento de Ahuachapán. El FMLN, históricamente formado por una difícil coalición de cinco facciones de izquierda, también sufrió divisiones internas sobre temas como su ideología, plataformas políticas, programas y políticas públicas en el contexto posterior a la guerra fría. Estos conflictos internos estallaron a finales de 1994, cuando siete legisladores dejaron el FMLN, junto con dos de los cinco partidos fundadores -la Resistencia Nacional (RN) y el Ejército Revolucionario del Pueblo (ERP)- (Zamora, 1998). Las bases de estos partidos disidentes permanecieron en las filas del FMLN o regresaron como simpatizantes. Por lo tanto, en la primera mitad del decenio de 1990 el FMLN luchó para superar las divisiones internas hasta convertirse en uno de los principales partidos de oposición en el sistema de partidos salvadoreño.

Durante este período, como la guerra civil terminó y el país vivía en paz, el sector de movimientos sociales y organizaciones de la sociedad civil también ajustaron sus estrategias y alianzas de conformidad con el nuevo clima político. Las organizaciones laborales tradicionales intentaron hacer frente a algunas de las medidas de austeridad de Cristiani a través de cortas campañas de protesta y huelgas de un día. Estas batallas de principios de la década de 1990 incluyen movimientos populares aglutinados en organizaciones tales como la Inter-Gremial y UNASTEMA que lucharon contra el desmantelamiento del IRA y de los despidos masivos en el sector público bajo el primer gobierno de ARENA. Algunos de los mayores conflictos sociales al estilo de movimiento social de la primera mitad de 1990, sin embargo, estaban centrados en temas que quedaron pendientes de la guerra civil, como las luchas de las asociaciones de campesinos y cooperativas rurales por el acceso a la tierra y los ex paramilitares (denominados patrulleros), que se enfrentaban al Estado a través de acciones callejeras violentas, exigiendo su indemnización y beneficios por servicios prestados al ejército durante la guerra civil.

En el fondo, El Salvador también estaba siendo transformado en una economía política neoliberal, especialmente en lo relacionado con la aplicación de una segunda generación de importantes reformas de política económica (Segovia 2002). La segunda etapa de reformas económicas fue centrada en la privatización, la dolarización y el libre comercio. Durante la presidencia de Armando Calderón Sol (1994-1999) se llevó a cabo un nuevo conjunto de privatizaciones, a través de las oficinas presidenciales del programa de Modernización del Estado. La modernización del Estado comenzó a generar problemas al final de 1994, con despidos masivos en el sector público (Anner, 1996). A principios de 1995, Calderón Sol anunció planes para aumentar el Impuesto al Valor Agregado (IVA), privatizar las telecomunicaciones (ANTEL), la distribución de energía eléctrica y el sistema estatal de pensiones. El movimiento popular, ONGs y el FMLN reaccionaron ante las reformas neoliberales con algunas movilizaciones y marchas en el transcurso de 1995, pero carecían de la capacidad para sostener una campaña unificada de oposición, dado el período de adaptación al nuevo entorno político neoliberal. 
En 1994 se celebraron elecciones locales, parlamentarias y presidenciales; el FMLN se estableció como un partido político importante al forzar una segunda vuelta electoral para la presidencia y ganar 21 escaños en la legislatura unicameral de 84 miembros (véase Tabla 2). Sin embargo, a nivel local, el FMLN sólo ganó 15 alcaldías, ninguna de las cuales se encontraba en un área metropolitana importante (mientras ARENA controlaba casi el 80 por ciento de los municipios) (véase Tabla 3). Los siete legisladores que abandonaron las filas del FMLN redujeron la representación del partido de izquierda en el parlamento a 14 escaños en 1995. Sin embargo, el FMLN siguió adelante con su estrategia de movilización electoral y mejoró sus resultados electorales en las elecciones parlamentarias y locales de 1997.

En las elecciones de 1997 el FMLN ganó 51 gobiernos municipales y 27 escaños legislativos (casi igualando al ARENA en la legislatura). Además, triunfó en la ciudad capital, con la elección del Dr. Héctor Silva como alcalde de San Salvador. Las elecciones de 1997 resultaron ser críticas, mientras el FMLN mantuvo su apoyo electoral en las elecciones locales y parlamentarias en 2000, 2003, 2004 y 2006 (Artiga-González, 2004) (véanse Tablas 2 y 3). A pesar de estos logros electorales sin precedentes para una organización política de izquierda en El Salvador, el partido no logró atraer el apoyo necesario para ganar una elección presidencial, las cuales perdieron en 1999 y 2004 en la primera ronda de votación (véase Tabla 1). Aunque una nueva ola de protesta surgida al principio de la década de 2000 ayudó al FMLN a mantener su representación local y parlamentaria, y tal vez lo llevaron a ganar la presidencia en 2009.

Sin embargo, la mayoría de la resistencia llevada a cabo por los sectores populares entre 1995 y 1998 estaba fragmentaba en sectores. Los trabajadores del sector de telecomunicación se movilizaron en contra de la privatización de ANTEL, la asociación de trabajadores públicos (ATMOP) luchó contra los despidos masivos, los trabajadores estatales en el sector de pensiones (SITINPEP) se opusieron a la privatización de las pensiones y las organizaciones no gubernamentales (ONGs) de defensa del consumidor se movilizaron en contra del Impuesto sobre el Valor Agregado y las alzas en los precios de la electricidad. En la mayoría de ocasiones entre 1994 y 1998, los sectores populares fueron incapaces de unificar sus luchas en una campaña más amplia, mientras que al mismo tiempo su principal aliado político dentro del Parlamento, el FMLN, no tenía el capital político para evitar la aprobación en el Parlamento de las medidas neoliberales. Sin embargo, cuando el gobierno inició la privatización del sistema público de salud a finales de 1999, el equilibrio de poder empezó a cambiar ligeramente en favor del movimiento popular y su resistencia a la liberalización del mercado.

En 1999, el tercer gobierno consecutivo de ARENA llegó al poder. El presidente Francisco "Paco" Flores (1999-2004) revivió una iniciativa, iniciada en la década de 1990 con la asistencia del Banco Mundial y el Banco Interamericano de Desarrollo, para la reestructuración del sistema hospitalario y el sistema de atención de salud. 
El programa de 1999 se centró en la externalización de los servicios médicos ofrecidos por el Instituto Salvadoreño del Seguro Social (ISSS). Los médicos del ISSS, que recién acababan de crear su sindicato en 1997 (SIMETRISSS), iniciaron en 1998 una campaña exitosa de huelga por mejores salarios y más voz en el proceso de reestructuración. De inmediato se unió al movimiento el sindicato de los trabajadores del ISSS (STISSS) para lanzar una campaña contra el intento del gobierno de privatización parcial de la salud. Esta campaña de protesta en particular resultó ser muy diferente a los episodios de resistencia a las políticas económicas en la década de 1990. STISSS y SIMETRISSS formaron amplias coaliciones con otros grupos de la sociedad civil y el partido FMLN (Almeida, 2006; Almeida, 2008b; Almeida y Delgado, 2008).

La amplia coalición contra la privatización de los servicios de salud fue posible gracias a una rearticulación de la estructura de la sociedad civil salvadoreña en la década de 1990. Después del fracaso de movilizaciones anteriores contra las reformas neoliberales (que fueron muchas veces aisladas y sectoriales), se constituyeron nuevas organizaciones y alianzas multisectoriales. Tal es el caso, en el sector laboral, del Movimiento de Organizaciones Laborales Integradas (MOLI), una coalición conformada por más de una docena de sindicatos del sector público. Además, en abril de 1998 se formó la Coordinadora Sindical de Trabajadores de El Salvador (CSTS) con siete federaciones sindicales y tres confederaciones y 37 organizaciones laborales provenientes del sector de la construcción, informal, y la industria de la maquila. Actuó como la mayor organización laboral de El Salvador a finales de 1990 y principios de 2000. Por último, en junio de 1999 surgió la Concertación Laboral y Social (CLS) como una coalición de trabajadores y organizaciones comunales para aglutinar a varios sectores sociales en la lucha contra la privatización, la represión estatal, aumentar del salario mínimo y evitar las reformas que querían aumentar la precariedad de los trabajadores a través la flexibilización laboral. En la estructura organizativa del MOLI y del CLS estaban representadas organizaciones de los empleados municipales, los maestros y varias otras organizaciones importantes, no pertenecientes al mundo laboral, tales como organizaciones estudiantiles BRES y la UERS-30, asociaciones campesinas y la confederación de las comunidades de base como la CORDECOM.

Desde el principio de 1999, a raíz de los desastres que dejó el Huracán Mitch, se formó una instancia de coordinación de las ONGs denominada Foro de la Sociedad Civil. El Foro contó por lo menos con cincuenta organizaciones no gubernamentales en sus filas, como la asociación de trabajadores agrícolas más importante, ANTA, Federaciones de Cooperativas Rurales (COACES y CONFRAS), así como importantes asociaciones rurales de base comunitaria (CORDES y CRIPDES). En el sector de la salud, la Comisión Tripartita se reunió en 1998 para defender la salud pública de cara al proceso de reestructuración del sistema. La Comisión Tripartita estaba conformada por el recién formado sindicato de los médicos del Instituto del Seguro Social Salvadoreño (SIMETRISSS), los médicos del sistema de hospitales públicos (MSPAS/AMENA) y el Colegio Médico -la asociación profesional de 
los médicos salvadoreños. Así, en 1999, en las vísperas de la primera huelga en contra de la privatización de la salud, se produjo una gran alianza entre docenas de organizaciones de los sectores laboral, campesino, estudiantil, profesional y de defensa de los consumidores. Ello significó realmente un cambio radical en la sociedad salvadoreña de la posguerra. Los médicos y trabajadores de la salud aprovecharon esta nueva red de asociaciones cívicas para iniciar dos de las huelgas más importantes en la historia salvadoreña y una de las campañas más largas en contra de la privatización en América Latina.

La primera huelga de los trabajadores en contra de la privatización de la salud se inició en noviembre de 1999 y duró hasta marzo de 2000. Se organizó una docena de marchas y concentraciones masivas en las principales ciudades del país, en el marco de una campaña de protesta pacífica. En algunos casos llegaron a participar más de 50.000 personas, provenientes de sectores tan diversos como los campesinos de Chalatenango y del Bajo Lempa, trasladados en autobuses hasta la capital para participar en las protestas en contra de la privatización. A la vez, los sindicatos del sector público organizaron cerca de una docena de huelgas de solidaridad. Las ONGs formaron una organización ad hoc, compuesta de unas 30 ONGs denominadas, el Movimiento de la Sociedad Civil Contra la Privatización (MSCCP), para apoyar la huelga de los trabajadores de la salud. Frente al masivo apoyo público del movimiento en contra de la privatización de la salud, el gobierno tuvo que ceder y negociar con STISSS y SIMETRISSS. Las protestas coincidieron con las elecciones legislativas y municipales del 2000. El FMLN apoyó públicamente la huelga y el movimiento social hizo campaña para el FMLN, lo cual explica en parte la victoria electoral de este partido en dichas elecciones. La izquierda obtuvo el control de un mayor número de gobiernos municipales y superó a ARENA por primera vez en el número de legisladores (véanse Tablas 2 y 3 ).

A mediados de 2002, el gobierno de ARENA, en colaboración con la Asociación de la Empresa Privada (ANEP), intentó una vez más la externalización de los servicios médicos en el ISSS. Esta acción provocó una huelga aún más larga, promovida por el STISSS y el SIMETRISSS, que duró entre septiembre de 2002 y junio de 2003. Los médicos y trabajadores de la salud llamaron de nuevo a los mismos aliados para apoyar la huelga y la defensa del sistema de salud pública. El Foro de la Sociedad Civil, y la Alianza Ciudadana contra la Privatización actuaron como principales coaliciones de la sociedad civil (integrada por ONGs, grupos de mujeres, sindicatos, cooperativas rurales y estudiantes) y jugaron un papel decisivo en la movilización de amplios sectores contra las medidas privatizadoras, por medio de bloqueos de las principales autopistas del país y la organización de marchas multitudinarias en algunas de las cuales participaron más de 200.000 personas (como, por ejemplo, las famosas "marchas blancas").

El FMLN, como partido político de oposición, se sumó a las protestas. Para ello no solo movilizó a militantes del partido, sino también a sus funcionarios electos, 
sus diputados y alcaldes. De hecho, toda la fracción parlamentaria del FMLN se sumó como parte integrante de las protestas en contra de la privatización de la salud. El FMLN también utilizó su mitin semanal conocido como Tribuna Abierta para llamar a sus partidarios a participar en las movilizaciones en contra de la privatización de salud. Por último, el partido de izquierda actuó como un aliado dentro de la Asamblea Legislativa mediante la introducción de una legislación que prohibía la privatización. La segunda huelga contra la privatización coincidió con las elecciones municipales y parlamentarias de 2003. Una vez más el FMLN se benefició de su apoyo abierto a la huelga, manteniendo su representación en la Asamblea Legislativa y en los gobiernos locales, incluido el control de la alcaldía capitalina. La huelga, una vez más, obligó al gobierno a poner fin a sus esfuerzos de externalización de los servicios médicos en el ISSS (Almeida, 2008a).

Después de junio de 2003, los sectores sociales y populares no fueron capaces de revivir el nivel de movilización que habían construido en sus batallas en contra de la privatización de la salud. Mientras tanto hubo una serie de movilizaciones de resistencia de menor envergadura por la protección del medio ambiente, en contra de la minería, la privatización del agua y de la firma del Tratado de Libre Comercio entre los Estados Unidos y Centroamérica y República Dominicana (conocida como CAFTA-DR, por su sigla en inglés). Entre 2004 y 2008, el gobierno de El Salvador aumentó la represión en contra de los movimientos populares, al tiempo que el movimiento social empezó a acercarse más al FMLN y sus aspiraciones electorales. En abril de 2004, la policía arrestó a los principales líderes del STISSS mientras intentaban ocupar la catedral metropolitana de San Salvador. En abril de 2005, el gobierno expulsó del país a un asesor clave de SIMETRISSS.

La verdadera movilización popular contra el CAFTA-DR empezó a finales de 2003 y principio de 2004. Un periódico conservador publicó los rostros de los presuntos líderes de los movimientos sociales que luchaban contra el TLC, mientras que la policía hostigaba a los vendedores informales de CD y DVD piratas, desde cuya actividad aseguran el sustento de su familia, por violar las reglas de propiedad intelectual del CAFTA. En 2006, después de un tiroteo ocurrido entre la policía y algunos manifestantes en frente de la Universidad Nacional de El Salvador, el gobierno aprobó una ley antiterrorista, la cual usaría posteriormente para procesar a los manifestantes de las principales ONGs del país por participar en una manifestación en contra de la privatización del agua, cerca de una localidad denominada Suchitoto, en julio de 2007. Mientras subían los costos personales y judiciales para los líderes de los movimientos populares de protesta a mediados de la década del 2000, el FMLN fue absorbiendo en sus campañas electorales a gran parte de la energía y simpatía popular con los movimientos de protesta.

Tras el éxito de las protestas en contra de la privatización de la salud, el FMLN incorporó dentro de su estructura organizativa a secciones de los movimientos sociales. A finales de 2003 se formó el Bloque Popular Social (BPS), que mantuvo estrechos vínculos con este partido. Otro movimiento popular, el Movimiento 
Popular de Resistencia 12 de Octubre (MPR-12), surgido en 2003, firmó un acuerdo de apoyo con el FMLN para las campañas electorales. Tanto el BPS y MPR 12 actuaron como vanguardia clave en las campañas contra el TLC entre 2004 y 2007. En 2004, el FMLN escogió a un importante líder de las huelgas en contra de la privatización de la salud, el Dr. Guillermo Mata Bennett (ex presidente del Colegio Médico), como candidato a la vicepresidencia para acompañar a su líder histórico, Jorge Schafik Hándal, como candidato a la presidencia. La campaña electoral de 2004 polarizó a la sociedad salvadoreña entre derecha e izquierda. A mediados de 2003, ARENA promulgó su política de Mano Dura para suprimir las pandillas callejeras violentas a través de detenciones masivas con la esperanza de obtener apoyo electoral en las próximas elecciones presidenciales (Cruz en prensa).

Tabla 1: Resultados de las elecciones presidenciales de ARENA y el FMLN, 1994-2009

\begin{tabular}{lcccc}
\hline Partido político & 1994 & 1999 & 2004 & 2009 \\
\hline ARENA & $\begin{array}{c}651.632 \\
\text { (primera vuelta) } \\
818.264\end{array}$ & 614.268 & 1.314 .436 & 1.284 .588 \\
& (segunda vuelta) & & & \\
& & & & \\
FMLN & $\begin{array}{l}331.629 \\
\text { (primera vuelta) } \\
378.980\end{array}$ & 343.472 & 812.519 & 1.354 .000 \\
& (segunda vuelta) & & & \\
\hline
\end{tabular}

Fuente: Tribunal Supremo Electoral.

Tabla 2: Resultados de elecciones legislativas de ARENA y el FMLN, 1994-2009*

\begin{tabular}{ccccccc}
\hline $\begin{array}{c}\text { Partido } \\
\text { político }\end{array}$ & 1994 & 1997 & 2000 & 2003 & 2006 & 2009 \\
\hline ARENA & $\begin{array}{c}606.211 \\
\text { (39 escaños) }\end{array}$ & $\begin{array}{c}396.301 \\
(28 \text { escaños })\end{array}$ & $\begin{array}{c}436.190 \\
(29 \text { escaños })\end{array}$ & $\begin{array}{c}446.381 \\
(27 \text { escaños })\end{array}$ & $\begin{array}{c}783.230 \\
(34 \text { escaños })\end{array}$ & $\begin{array}{c}854.166 \\
(32 \text { escaños })\end{array}$ \\
FMLN & $\begin{array}{c}287.811 \\
(21 \text { escaños })\end{array}$ & $\begin{array}{c}369.709 \\
(27 \text { escaños })\end{array}$ & $\begin{array}{c}426.298 \\
(31 \text { escaños })\end{array}$ & $\begin{array}{c}475.146 \\
(31 \text { escaños })\end{array}$ & $\begin{array}{c}785.072 \\
(32 \text { escaños })\end{array}$ & $\begin{array}{c}943.936 \\
\text { (35 escaños) }\end{array}$ \\
\hline
\end{tabular}

*El Salvador tiene un sistema parlamentario unicameral con 84 escaños.

Fuente: Tribunal Supremo Electoral y Artiga, Álvaro, El sistema electoral salvadoreño de posguerra (1994-2007). San Salvador, El Salvador: FundaUngo, 2008. 
Tabla 3: Resultados de las elecciones municipales de ARENA y el FMLN, 1994-2009

\begin{tabular}{|c|c|c|c|c|c|c|}
\hline $\begin{array}{l}\text { Partido } \\
\text { político }\end{array}$ & 1994 & 1997 & 2000 & 2003 & 2006 & 2009 \\
\hline \multirow[b]{2}{*}{ ARENA } & $\begin{array}{c}\text { Total } \\
\text { votos: } \\
598.391\end{array}$ & $\begin{array}{c}\text { Total } \\
\text { votos: } \\
410.537\end{array}$ & $\begin{array}{c}\text { Total } \\
\text { votos: } \\
438.859\end{array}$ & $\begin{array}{c}\text { Total } \\
\text { votos: } \\
491.452\end{array}$ & $\begin{array}{c}\text { Total } \\
\text { votos: } \\
791.361\end{array}$ & $\begin{array}{c}\text { Total } \\
\text { votos: } \\
867.273\end{array}$ \\
\hline & $\begin{array}{l}\text { Concejos } \\
\text { municipales } \\
\text { ganados: } \\
207\end{array}$ & $\begin{array}{c}\text { Concejos } \\
\text { municipales } \\
\text { ganados: } \\
160\end{array}$ & $\begin{array}{c}\text { Concejos } \\
\text { municipales } \\
\text { ganados: } \\
127\end{array}$ & $\begin{array}{c}\text { Concejos } \\
\text { municipales } \\
\text { ganados: } \\
111\end{array}$ & $\begin{array}{c}\text { Concejos } \\
\text { municipales } \\
\text { ganados: } \\
147\end{array}$ & $\begin{array}{c}\text { Concejos } \\
\text { municipales } \\
\text { ganados: } \\
122\end{array}$ \\
\hline \multirow[b]{2}{*}{ FMLN } & $\begin{array}{c}\text { Total } \\
\text { votos: } \\
276.124\end{array}$ & $\begin{array}{c}\text { Total } \\
\text { votos: } \\
365.175\end{array}$ & $\begin{array}{c}\text { Total } \\
\text { votos: } \\
415.003\end{array}$ & $\begin{array}{c}\text { Total } \\
\text { votos: } \\
471.042\end{array}$ & $\begin{array}{c}\text { Total } \\
\text { votos: } \\
670.711\end{array}$ & $\begin{array}{c}\text { Total } \\
\text { votos: } \\
886.161\end{array}$ \\
\hline & $\begin{array}{c}\text { Concejos } \\
\text { municipales } \\
\text { ganados: } \\
15\end{array}$ & $\begin{array}{c}\text { Concejos } \\
\text { municipales } \\
\text { ganados: } \\
54\end{array}$ & $\begin{array}{c}\text { Concejos } \\
\text { municipales } \\
\text { ganados: } \\
79\end{array}$ & $\begin{array}{c}\text { Concejos } \\
\text { municipales } \\
\text { ganados: } \\
74\end{array}$ & $\begin{array}{c}\text { Concejos } \\
\text { municipales } \\
\text { ganados: } \\
59\end{array}$ & $\begin{array}{c}\text { Concejos } \\
\text { municipales } \\
\text { ganados: } \\
96\end{array}$ \\
\hline
\end{tabular}

Fuente: Tribunal Supremo Electoral y Artiga, Álvaro El sistema electoral salvadoreño de posguerra (1994-2007). San Salvador, El Salvador: FundaUngo, 2008.

Durante la campaña presidencial de 2004 el FMLN utilizó la red del partido y se movilizó como un movimiento social, haciendo campaña de puerta a puerta en busca del apoyo electoral de la gente. Al final, el candidato presidencial de ARENA, Antonio Saca, obtuvo un récord de 1.314 .000 votos. Sin embargo, el FMLN también duplicó su votación con respecto a elecciones presidenciales anteriores, con más de 800.000 votos (véase Tabla Uno). En las elecciones legislativas y municipales del 2006, el FMLN mantuvo su representación en el Parlamento y recibió más de 780.000 votos (véase Tabla 2). Este éxito electoral es también notable, dados los cismas que el partido experimentó con la deserción de varios miembros de su fracción. El FMLN también se benefició de la impopularidad de las políticas gubernamentales tales como la privatización, la incapacidad para controlar la inflación y otras cuestiones conexas (por ejemplo, la corrupción oficial, el envío de tropas salvadoreñas a Irak, etc.). Después de que las protestas contra el CAFTA alcanzaron su máximo nivel en el 2006, los altos costos de la vida, el transporte y gastos médicos siguieron siendo una fuente importante de quejas de la sociedad civil. La Figura 1 ilustra el aumento en la inflación en la era posterior a la guerra civil (1993-2009). Especialmente destacable es el aumento de los costos de la vivienda, medicina, comida y transporte en los meses anteriores a la campaña para las elecciones presidenciales de 2009. 
Figura 1: Inflación en El Salvador, 1993-2009

(Por mes) Índice diciembre $1992=100$

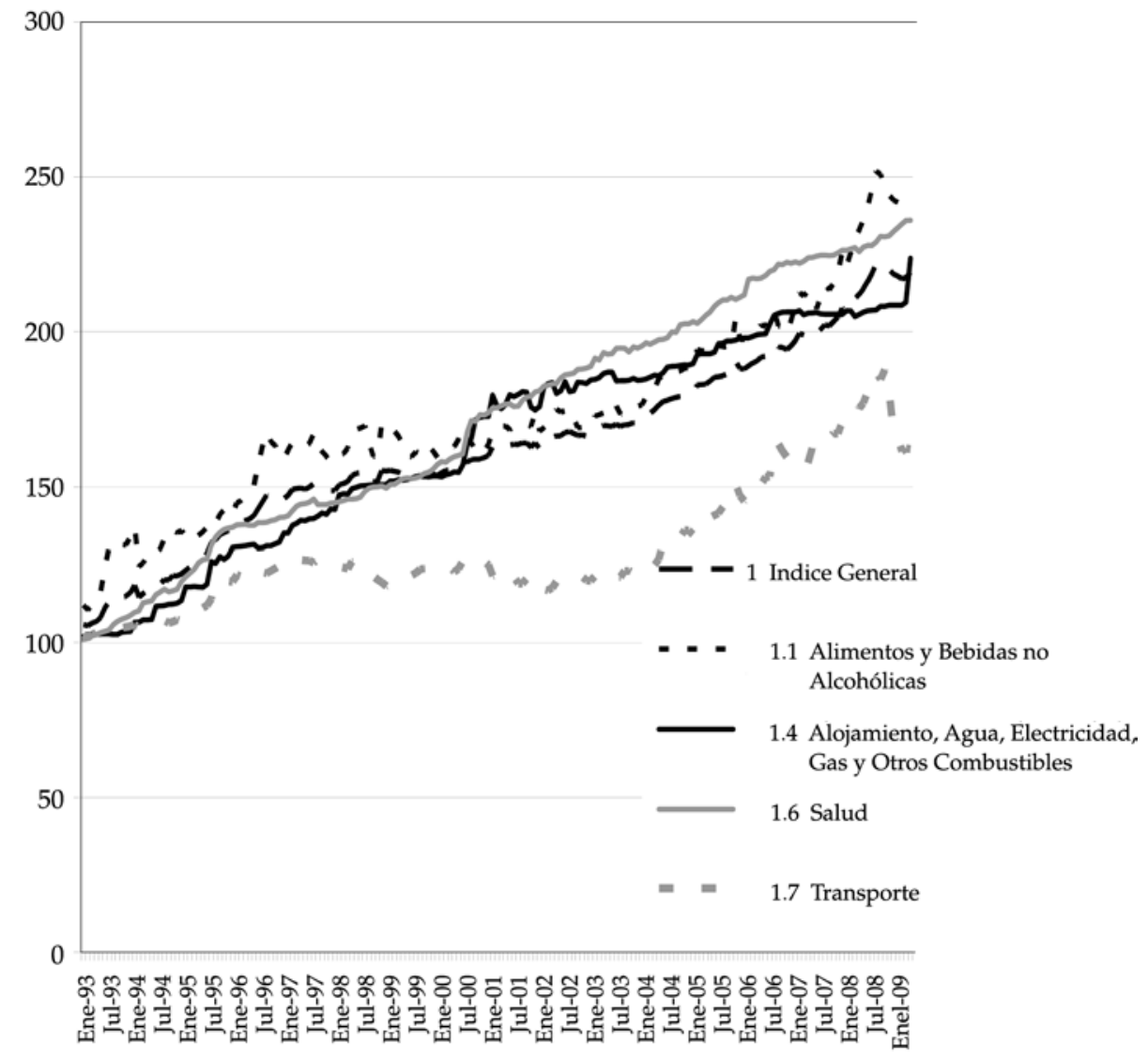

Fuente: Dirección General de Estadística y Censos (Ministerio de Economía).

El mantenimiento de los logros electorales del FMLN a nivel municipal y parlamentario a principios y mediados de 2000 sentó las bases para sus extraordinarios resultados electorales en las elecciones presidenciales de 2009. Incluso en la víspera del lanzamiento de la campaña presidencial de 2009, a finales de agosto de 2007, el FMLN invitó a varias organizaciones cívicas, movimientos sociales y organizaciones no gubernamentales a la Asamblea Legislativa para impulsar la aprobación de una ley nacional que prohibiría la privatización del agua, la cual las organizaciones venían impulsando en el Parlamento desde 2006. El jefe de la facción parlamentaria del FMLN, Salvador Sánchez Cerén, quien a la postre se convertiría en candidato a la vicepresidencia, exhortó a la multitud de asistentes de organizaciones no gubernamentales activas en el sector del movimiento social que "la lucha por la defensa del agua iba a requerir la movilización de parte de las comunidades" (en Leiva, 2007). 
El FMLN también se benefició de la paulatina caída en la popularidad de los sucesivos presidentes de ARENA. Encuestas de opinión pública llevadas a cabo por la Universidad Centroamericana "José Simeón Cañas" muestran que el Presidente de ARENA Antonio Saca (2004-2009) tuvo menos apoyo público que su antecesor Francisco "Paco" Flores (1999-2004). La Tabla 4 compara la opinión pública en el año final de ambos presidentes con el mismo indicador. Los datos sugieren que la ciudadanía vio más negativamente la situación del país bajo el Presidente Saca que bajo el Presidente Flores, inclusive en el área de las condiciones económicas. La disminución de rendimiento percibido de los presidentes de ARENA también ayudó a crear un clima propicio en la búsqueda de un candidato de oposición fuerte para desafiar al partido ARENA que ya llevaba veinte años de monopolio del Poder Ejecutivo. Al mismo tiempo, otros investigadores han demostrado en este mismo período un cambio moderado hacia la izquierda política del electorado salvadoreño en su conjunto (Reverse, 2009).

Tabla 4: Comparación de las presidencias de Flores y Saca (ARENA) en su último año de gobierno

\begin{tabular}{|c|c|c|c|c|}
\hline \multirow{2}{*}{$\frac{\text { Pregunta }}{\text { ¿Ha notado usted algún cambio positivo }}$} & \multicolumn{2}{|c|}{$\begin{array}{c}\text { Francisco Flores } \\
\text { (Mayo 2004) }\end{array}$} & \multicolumn{2}{|c|}{$\begin{array}{c}\text { Antonio Saca } \\
\text { (Abril-mayo 2009) }\end{array}$} \\
\hline & Sí & $(67,1 \%)$ & Sí & $(49,6 \%)$ \\
\hline en nuestro país desde que entró Francisco & No & $(32,9 \%)$ & No & $(50,4 \%)$ \\
\hline Flores/Antonio Saca como Presidente? & & $\mathrm{N}=1.044$ & & $\mathrm{~N}=1.255$ \\
\hline \multirow{4}{*}{$\begin{array}{l}\text { En su opinión, ¿el país está mejor, } \\
\text { igual o peor que cuando entró el actual } \\
\text { gobierno? }\end{array}$} & Mejor & $(39,1 \%)$ & Mejor & $(17,2 \%)$ \\
\hline & Igual & $(34,7 \%)$ & Igual & $(38,7 \%)$ \\
\hline & Peor & $(26,2 \%)$ & Peor & $(44,2 \%)$ \\
\hline & & $\mathrm{N}=1.041$ & & $\mathrm{~N}=1.257$ \\
\hline \multirow{4}{*}{$\begin{array}{l}\text { ¿Cree usted que la situación económica } \\
\text { del país ha mejorado o ha empeorado } \\
\text { con el actual gobierno? }\end{array}$} & Ha mejorado & $(21,7 \%)$ & Ha mejorado & $(9,1 \%)$ \\
\hline & Sigue igual & $(22,7 \%)$ & Sigue igual & $(25,0 \%)$ \\
\hline & Ha empeorado & $(55,6 \%)$ & Ha empeorado & $(66,0 \%)$ \\
\hline & & $\mathrm{N}=1.042$ & & $\mathrm{~N}=1.258$ \\
\hline
\end{tabular}

Fuente: IUDOP. 2004. “Encuesta de evaluación del quinto año de gobierno de Francisco Flores, Asamblea Legislativa y Alcaldías". Serie de informes 105 y IUDOP. 2009. "Encuesta de evaluación del gobierno de Antonio Saca, Asamblea Legislativa y Alcaldías y expectativas hacia el Nuevo gobierno". Serie de informes 120.

A finales de 2007, el partido ratificó a Mauricio Funes y Salvador Sánchez Cerén como sus candidatos a la presidencia y vicepresidencia, respectivamente. Funes era un conocido periodista de investigación con décadas de exposición en la televisión en El Salvador. También es una persona ajena al partido. Sánchez Cerén inició sus andaduras políticas en el movimiento popular a finales de 1960 como líder de la Asociación de Maestros ANDES-21 de Junio, del departamento de La Libertad. También fue uno de los más altos dirigentes de las Fuerzas Populares de Liberación (FPL) hasta que el partido se disolvió en el FMLN en 1995. 
Los candidatos del FMLN iniciaron su campaña en un estadio de fútbol, el estadio Cuscatlán, el 11 de noviembre de 2007, ante la presencia de unos 50.000 asistentes, casi un año y medio antes de las elecciones que se celebrarían en marzo de 2009 (ARENA no eligió sus candidatos hasta marzo de 2008). La campaña de Funes, denominada la "Caravana de la Esperanza" (similar a la campaña de "esperanza" de Barack Obama), utilizó de manera inteligente los 17 meses de que disponía. La caravana viajó por varios municipios cada fin de semana como un medio para transmitir el mensaje de la campaña. Los mítines se parecían a las reuniones populares de los movimientos de protesta, con las mismas consignas y cantos populares y otras que se crearon para la ocasión.

La campaña de Funes también obtuvo el apoyo de varias emisoras de radio. Incluso una radio de alcance nacional muy importante, como Radio Mi Gente, fundada por un ministro evangélico. Radio Mi Gente emitía diariamente en favor del cambio social y pone de relieve los graves problemas sociales y económicos que padecen las clases populares de El Salvador, como la violencia de pandillas, la corrupción oficial y el alto costo de la vida. Radio Mi Gente, Radio Maya Visión, la Caravana de Esperanza, y un ejército de voluntarios de la campaña también distribuían y vendían canciones de protesta en apoyo de la campaña. Músicos nacionales compusieron decenas de nuevas canciones para acompañar la movilización electoral en varios ritmos populares como cumbia, merengue, mariachi, ranchera, y reggaeton. Todas estas estrategias de comunicación popular podrían verse como la superación de las deficiencias de campañas electorales pasadas donde los partidos políticos de derecha controlaban las tres principales cadenas de televisión nacional y las ondas de radio más importantes.

La movilización electoral del FMLN del 2009 tuvo su primera prueba de fuego con las elecciones municipales y legislativas celebradas el 18 de enero de 2009. El FMLN perdió la comuna capitalina, San Salvador, a manos de ARENA, por un estrecho margen (el FMLN había derrotado a ARENA por un margen aún menor en 2006). Sin embargo, el FMLN triunfó en más de 90 gobiernos municipales y ganó 35 escaños en la Asamblea Legislativa (la más alta cantidad de gobiernos locales y diputados obtenidos hasta ahora por el partido) (véanse Tablas 2 y 3 ). En los últimos dos meses antes de las elecciones presidenciales los candidatos de los partidos más pequeños se retiraron de la carrera presidencial para garantizar un enfrentamiento final entre el FMLN y ARENA que se decidió en la primera vuelta electoral. Los "Amigos de Mauricio", un grupo que atrajo el apoyo de personas descontentas con otros partidos políticos, militares, empresarios y parte del grupo de los cristianos evangélicos, jugaron un papel fundamental en los últimos meses de la campaña.

La prueba final antes de las elecciones para el FMLN tuvo lugar el sábado 7 de marzo 2009, una semana antes de las elecciones. Funes y el FMLN convocaron a un mitin electoral final en San Salvador, en la avenida conocida como la Alameda Juan Pablo II. La reunión resultó ser uno de los mayores eventos políticos en 
la historia salvadoreña. Una multitud se extendía desde los alrededores del municipio de Soyapango hasta el Centro de Gobierno. Se establecieron distintas tarimas desde donde se difundían músicas en directo y consignas políticas. Se estimó que participaron más de 300.000 personas en este evento (Romero Pineda, 2009). Las 300.000 personas reunidas para la circunstancia quizá no escucharon la exhortación que les hacía el candidato Funes en este evento de llevar cada uno a cerca de otros 10 votantes más a la causa de su partido; sin embargo, los simpatizantes del FMLN fueron capaces de llevar al menos a cuatro adherentes más a la votación final la semana posterior. El conteo final de las elecciones dieron como resultado 1.354.000 votos para el FMLN y 1.284.588 para ARENA (véase Tabla 1).

Desde que asumió el poder en junio de 2009, Funes tiene la poco envidiable tarea de moderar las expectativas de los simpatizantes del FMLN en medio de una crisis financiera mundial. El gobierno de Funes ha tenido enfrentamientos internos con el FMLN en temas relacionados con la política exterior y la reducción de las tarifas telefónicas. Sin embargo, el conflicto de élite más importante desde que se conocieran los resultados de las elecciones de 2009 se produjo al interior del partido ARENA, otrora conocido por su unidad granítica. A finales de 2009, 12 diputados dejaron el partido, cuestionando la integración del Consejo Ejecutivo de ARENA (COENA) y la estrategia electoral en la campaña para las presidenciales de 2009. Los miembros disidentes de ARENA iniciaron en 2010 la formación de un nuevo partido de raigambre conservador, denominado la Gran Alianza por la Unidad Nacional (GANA) y formaron su propia facción legislativa en el Parlamento salvadoreño (Freedman, 2009).

El nuevo gobierno de Funes también está experimentando con nuevas iniciativas sociales prometidas durante la campaña presidencial, como el Foro Nacional de la Salud. El Foro convoca asambleas populares en cinco regiones en 2010 con el fin de diseñar un nuevo plan de salud pública que facilite una mayor cobertura médica a la población. Los movimientos sociales que participaron en las campañas en contra de la privatización de la salud coordinan los Foros con el Ministerio de Salud Pública y Asistencia Social (MSPAS). Los movimientos sociales continúan movilizándose en la calle, por ejemplo, en temas relacionados con la minería en los departamentos del Norte de El Salvador. Sigue siendo una pregunta abierta sobre cómo la nueva "marea rosa" de gobiernos de izquierda en la región, como el caso del FMLN en El Salvador, responderán ante las presiones desde abajo de los sectores populares que los han llevado al Poder Ejecutivo a principios del siglo XXI.

\section{REFERENCIAS}

Almeida, Paul. 2006. "Social Movement Unionism, Social Movement Partyism, and Policy Outcomes", in H. Johnston and P. Almeida, eds., Latin American Social Movements: Globalization, Democratization, and Transnational Networks (Rowman and Littlefield, 2006), 57-73. 
Almeida, Paul. 2008a. Waves of Protest: Popular Struggle in El Salvador, 1925-200. Minneapolis: University of Minnesota Press.

Almeida, Paul. 2008b. "The Sequencing of Success: Organizing Templates and Neoliberal Policy Outcomes", Mobilization 13, $\mathrm{N}^{\mathrm{0}}$ 2: 165-87.

Almeida, Paul and Roxana Delgado. 2008. "Gendered Networks and Health Care Privatization", Advances in Medical Sociology 10: 277-303.

Anner, Mark. 1996. “¿Hacia la sindicalización de los sindicatos?” Estudios Centroamericanos N ${ }^{\circ}$ 573-574: 599-614.

Artiga-González, Álvaro. 2004. Elitismo competitivo: dos décadas de elecciones en El Salvador (1982-2003). San Salvador: UCA Editores.

Artiga-González, Álvaro. 2008. El sistema electoral salvadoreño de posguerra (1994-2007). San Salvador, El Salvador: FundaUngo.

Brockett, Charles. 2005. Political Movements and Violence in Central America. Cambridge: Cambridge University Press.

Cruz, José Miguel. 2011. En prensa. "Government Responses and the Dark Side of Gang Suppression in Central America", in Tom Bruneau and Jeanne Giraldo, eds., The Maras and Security Challenges in Central America and the U.S. Austin: University of Texas Press.

Freedman, Elaine. 2009. "GANA's Birth Is ARENA's Loss", Revista Envío Número 341, diciembre.

Gould, Jeffrey and Aldo Lauria-Santiago. 2008. To Rise in Darkness: Revolution, Repression, and Memory in El Salvador, 1920-1932. Durham: Duke University Press.

Leiva, Santiago. 2007. "FMLN exhorta a luchar porque el agua no se convierta en mercancía". Diario Colatino, August 29.

Lindo-Fuentes, Héctor, Erik Ching, and Rafael A. Lara-Martínez. 2007. Remembering a Massacre in El Salvador: The Insurrection of 1932, Roque Dalton, and the Politics of Historical Memory. Albuquerque: University of New Mexico Press.

Reverse, Roody. 2009. "Las Elecciones de 2009 en El Salvador: avances y retos de la democracia". Nueva Sociedad (Nov./Dec.) 224: 4-17.

Robinson, William I. 2003. Transnational Conflicts: Central America, Social Change and Globalization. London: Verso.

Robinson, William I. 2008. Latin America and Global Capitalism: A Critical Globalization Perspective. Baltimore: Johns Hopkins University Press.

Romero Pineda, Luis. 2009. “Torrente rojo de 300 mil personas", Diario CoLatino, March 9.

Segovia, Alexander. 2002. Transformación estructural y reforma económica en El Salvador. Guatemala City: F\&G Editores.

Stanley, William 1996. The Protection Racket State: Elite Politics, Military Extortion, and Civil War in El Salvador. Philadelphia: Temple University Press.

Williams, Philip and Knut Walter. 1997. Militarization and Demilitarization in El Salvador's Transition to Democracy. Pittsburgh: University of Pittsburgh Press.

Wolf, Sonja. 2009. "Subverting Democracy: Elite Rule and the Limits to Political Participation in Post-War El Salvador". Journal of Latin American Studies 41: 429-465.

Zamora, Rubén. 1998. El Salvador, heridas que no cierran: los partidos políticos en la post-guerra. San Salvador: FLACSO.

Paul Almeida es profesor asociado de sociología en la Universidad de California Merced. Es el autor de Waves of Protest: Popular Struggle in El Salvador, 1925-2005 (University of Minnesota Press, 2008) and co-editor, con Hank Johnston, de Latin American Social Movements: Globalization, Democratization, and Transnational Networks (Rowman \& Littlefield, 2006). 